\title{
São Paulo: exercício de memória
}

\author{
CARLOSGUILHERME MOTA
}

Para Sérgio M illiet e Luís Saia, in memoriam.

- M SeU desenvolvimento histórico, São Paulo foi muitas vezes comparada a Liverpool, M anchester, C hicago, M ilão. N o dealbar de um novo século, ocorre-nos perguntar: como São Paulo al cançou o século XX? C omo se transformou numa das três maiores e problemáticas metrópoles do planeta, que desafiam a inteligência de urbanistas, historiadores, cientistas sociais, arquitetos e políticos, para não dizer a sensibilidade de seus cidadãos?

D ebuxar, num rápido apanhado, a história que nos trouxe à contemporaneidade, nestas partes, eis o objetivo deste ensaio. Ensaio de risco, necessariamente lacunar, de vez que a historiografia sobre região vem se aprofundando muitíssimo, sobretudo nos últimos vinte anos, revelando aspectos e sentido de uma história regional que - curioso paradoxo - estavam na sombra. H istória rica e cheia de desafios, a começar pela situação marginal em que se achava relegada a C apitania no período colonial, depois tendo vivido o boom do café no século XIX, a mal-acabada abolição em 1888 do trabalho escravo e, na seqüência, mudanças profundas com o impacto da imigração em massa e, já no século XX, com a industrialização.

Em 1990, num de seus incisivos diagnósticos debatidos no IEA, M ilton Santos notava que a região de São Paulo praticamente já nascera moderna. Tanto pelo lado da produção, como pelo lado do consumo. I sso, graças à importação, pelos imigrantes, de hábitos e aspirações, mas também pelo meio ambiente construído, propício às transformações. N o Brasil, segundo o geógrafo-urbanista, a mecanização do espaço geográfico ocorre com maior força na hinterlândia paulista, criando as condições para uma expansão sustentada. M ais, constatava M ilton: "A cada movimento renovador da civilização material nos países centrais, São Paulo e o seu retro país reagem afirmativamente, adotando o novo com presteza e assim, reciprocamente, gerando crescimento" ${ }^{1}$.

Q ual o sentido geral dessa história estressada, que nos convoca ao presente, nervosamente, numa era de reconstrução como a que se vive nesta cidade tão machucada, sobretudo por conta das duas últimas administrações brutalizantes?

Com efeito, o crescimento do maior conglomerado do subcontinente, capital do Estado, com sua constelação de cidades de grande porte (Santos, Campinas, Ribeirão Preto, São José dos Campos, além das vizinhas São Caetano, Santo André, São Bernardo e Diadema), a verticalização em ritmo vertiginoso após os anos de 1930, a massificação e a cosmopolitização dos costumes e men- 
talidades criaram o diferencial que elevou São Paulo à condição de grande metrópole. Tempos históricos, sistemas de representação e formações histórico-culturais distintas nela se superpõem, ora se completando, ora se anulando, ou até mesmo se apagando. O ra gerando estímulos, como agora, para novas formas de pensamento e expressão urbanísticas, sociais, ideológicas, artísticas de uma nova sociedade civil democrática. Tempo plural o desta metrópole desvairada, que nos desdobra em trezentos, provocando comoções em nossas vidinhas piraquaras.

Exercício de memória, talvez estas notas sirvam para construir um pequeno espelho para nos mirarmos. E tentarmos mudar a rota, nosso padrão civilizatório, numa direção menos insatisfatória e mais humanista. Em verdade, dar-nos a chance de sair da ideologia do timing, dessa pressa da sociedade do espetáculo e da cultura do marketing, e reencontrarmos nosso andamento próprio, sereno.

\section{Três momentos, em busca da identidade}

Examinemos três momentos que possuem alguma coerência interna, a que podemos denominar "épocas". Afinal, que são épocas, senão a existência, num determinado lapso temporal, de formações econômi co-culturai s com certa unidade, com dinâmicas específicas, valores e costumes próprios? Formações que, ao longo do tempo/ processo, foram se adensando, se transformando uma na outra, com poucas rupturas aparentes, forjando uma certa identi dade. I dentidade legível na construção histórica de uma mentalidade própria, de um sistema de representacões e de uma mitologia que expressa um tipo de consciência coletiva que, na falta de melhor qualificativo, denominaremos de "paulista". O u seja, um conjunto de hábitos em que operosidade, competitividade, espírito empreendedor, sentido de contrato econômico e social, de resistência, de respeito relativo ao cumprimento de horários etc. esboçam um certo perfil. De resto, perfil assemeIhável ao encontrado em regiões e momentos de expansão - ou crise - do sistema capitalista, em outras épocas e contextos.

Q uando buscamos alguma "identidade", não nos esquecemos de suas diferentes "leituras" conforme as classes, os estamentos ou até mesmo castas considerados; por identidade referimo-nos, antes, a um perfil ou conjunto de atitudes e valores ao qual adere e reforça o conjunto social regional, em sua historicidade e contradições próprias, definido sobretudo pelos migrantes de variadas classes sociais, provenientes de outras regiões do país e do Exterior. "São Paulo é um ímã muito forte", conforme expressão utilizada por Edinalva de Souza, uma jovem negra, recém-chegada do sertão baiano à capital do Estado para trabalhar como empregada doméstica, nos anos de 1970.

Ademais, o fenômeno não é exclusivo do Brasil ou de São Paulo. Em outros variadíssimos tempos e lugares, os "afrancesados", "anglicizados" ou "americanizados" são bastante conhecidos. 0 antropólogo Claude Lévi-Strauss não se surpreendeu também com a quantidade de "afrancesados", na cidade de São Paulo e na U SP, na primeira metade do século passado, tendo encontrado difi- 
culdade em exercitar-se na língua portuguesa, pois seus alunos/ convivas, quase todos, expressavam-se e "pensavam" em francês...

Portanto, identidadetem muito a ver com o próprio fenômeno imigratório: tantos foram e continuam sendo os embates, que uma certa maneira de ser "moderna" e "cidadã" se exercita e robustece. $\mathrm{N}$ ão por acaso, parcela significativa das lideranças da nova soci edade civil - na vida sindical, na universidade, nas igrejas, no empresariado e na produção tecnológica - para cá se dirigiram e se formaram nesta precisa constelação de cidades, polarizadas por São Paulo. Lula, de Pernambuco, é apenas um exemplo.

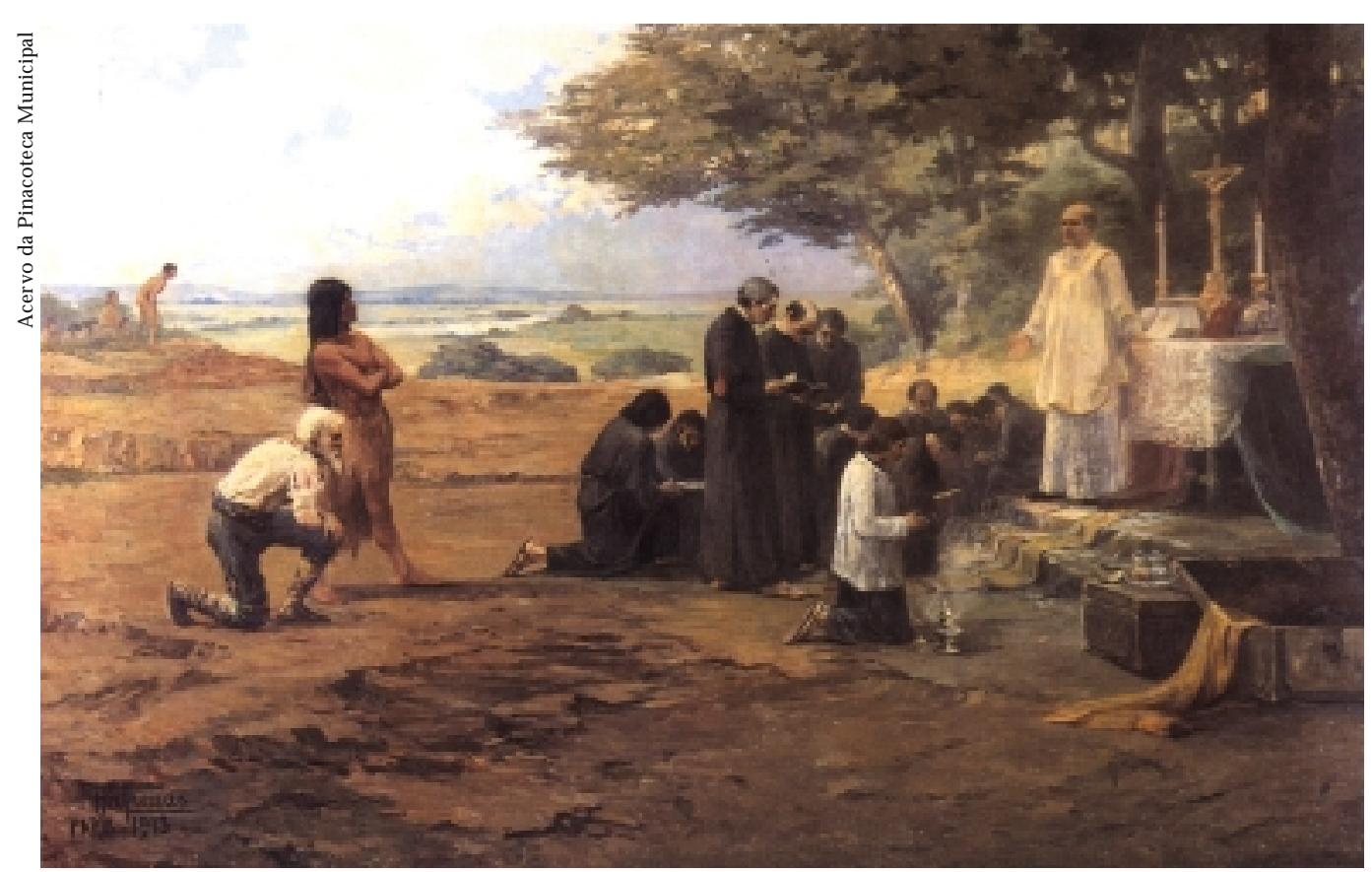

Fundação de São Paulo, 1913, 0.s.t., 179 x 279,5 cm, por A ntonio Diogo da Silva Parreiras

\title{
I Das origensà Independência: a ci dade coloni al. U m "coração alto, grande e ani moso".
}

\author{
Pelas vielas do povoado, ou através das lavouras, deslizam sombras. \\ Rebanhos trágicos de negros da terra ou da Guiné. \\ M amelucos madraços e atrevidos. Potentados de grande séquito, \\ cheios de rudeza e gravidade, que passam e de repente \\ desaparecem, tragados pelo sertão. \\ Alcantara M achado ${ }^{2}$.
}

Q uem caminhar hoje pelo espigão da avenida Paulista, na intensa cidade de São Paulo, ou flanar pelas ruas adjacentes, talvez não suspeite que há seis séculos, antes mesmo do Descobrimento, já havia vida social nesta região. U m "misterioso povo serrano" aqui vivia. 
De fato, os portugueses, fixados num povoado na ilha de São Vicente, mantinham "assíduas relações com o gentio de serra acima". D aí partiram nas duas primeiras décadas do século XVI, galgando a Serra do M ar ("de gatinhas" para não despencarem, segundo o padre Anchieta) e topando no Planalto com uma trilha a que os índios Tupi denominavam peabirú. Essa vereda ancestral, aberta não se sabe quando em meio a densa vegetação, seria por eles chamada de estrada real - ou, pelos espanhóis, de camino real -, articulando São V icente ao Paraguai. Esse "Campo", como se denominava o Planalto, situava-se numa das principais encruzilhadas do $\mathrm{N}$ ovo $\mathrm{M}$ undo, onde quatro séculos depois se implantaria, junto aos rios Tietê e Tabatinguera, uma das maiores metrópoles do planeta.

C omo se sabe, desde o início da colonização, o governo português estimularia progressivamente a exploração de produtos agrícolas (açúcar, pau-brasil, fumo) ao longo do litoral. 0 interior ficou mais vinculado à iniciativa particular, pessoal, que se desenvolveu por meio de incursões de longa duração, efetuadas por um tipo de mestiços que eram chamados de mamelucos, paulistasou bandeirantes. Esse modo de vida, de hábitos e de mentalidade plasmou uma civilização essencial mente rural, com os índios sendo reduzidos ao cativeiro. O s plantadores espalhavam-se à volta dos pequenos aglomerados urbanos, acorrendo à vila somente para a missa e os festejos. Foi-se criando um núcleo urbano que alguns historiadores definiram como "autarquia paulista", com espírito bastante diferente da metrópole portuguesa ou do N ordeste; os nomes das aldeias, rios, acidentes geográficos dão conta do caráter localista, fortemente marcado pela cultura indígena. $\mathrm{N}$ ada que se pudesse comparar às grandes cidades portuárias como Salvador, O linda e Rio, ou com a intensa vida comercial nas cidades do M éxico ou de Lima, na A mérica Espanhola.

Longe do braço do Estado português, São Paulo tornou-se mais tarde refúgio de cristãos-novos, ou criptojudeus. N esta região sul, havia quatro capitanias: a do Rio de J aneiro (a principal), Santo Amaro, N ossa Senhora da Conceição de I tanhaém e São Vicente. M uito ligadas, formavam um bloco, denominadas "capitanias de baixo", ou de São Vicente, simplesmente. Levava-se aí uma vida bem rústica e quieta, se comparada com a riqueza e o burburinho da Bahia e de O linda.

São Paulo, tornada vila em 1561, localizava-se no planalto, onde habitava uma po pulação indígena com hábitos antropofágicos, que inspirariam os vorazes modernistas do século XX. E as guerras entre as tribos multiplicaram-se com as migrações contínuas a que estavam habituados. A ação européia no século XVI (com grande presença de franceses, alemães e espanhóis nestas partes, além dos portugueses, que dominaram ao longo do período) afirmou-se com a preação de índios, ou seja, a escravização dessa mão-de-obra, dos "negros da terra", para a implantação de suas roças e lavouras. Com a fuga e o recuo dos nativos para a hinterlândia, ampliou-se a perseguição pelo interior por meio de expedições, incen- 
tivada também (e sobretudo) pela busca de um Paraíso perdido, numa série de migrações motivadas pela busca de ouro, prata e de jazidas de esmeralda.

$\mathrm{N}$ a confluência de interesses comerciais, São Paulo de Piratininga passou em 1711 de vila a cidade. D ela partiam "bandeiras", em busca de indígenas e de metais preciosos. Sua população era pobre demais, miserável, para comprar escravos negros para a lavoura, como o faziam os senhores de engenho da Bahia e de Pernambuco. Os "bandeirantes"...

0 mito do bandeirante é bastante discutível e o próprio o termo parece mesmo não ter existido antes do século XVIII. Esses preadores eram chamados "mamelucos", ou "gente de São Paulo", ou "portugueses de São Paulo", como que já distinguindo um tipo humano diverso do litorâneo, mais afeito às coisas e aos hábitos do sertão, como a rede e a farinha "de pau". O historiador inglês Charles Boxer menciona uma pitoresca visão de São Paulo, a partir de um trecho de A Vanished A rcadia, de C unninghame-Graham, do começo do século XX:

São Paulo era um ninho de piratas e esconderijo de todos os valentões do Brasil e do Paraguai. Essa gente, não encontrando mulheres com quem se pudesse unir para transmitir suas virtudes, atiravam-se àsíndias eàs negrinhas, fazendo vir ao mundo uma raça dez vezes pior do que ela própria, como é freqüente acontecer, na América, com os mestiços e mulatos [... ]

N esse caldo racista, o que não fica dito é que as índias foram, em sua maioria, as primeiras matriarcas da sociedade que se formou aqui. Como escreveu 0 professor Boxer: "Em 1614, a raça mestiça de lusos e índios constituía o grosso da população das capitanias do sul". Tal mistura contrastava com o que se passava na Bahia e em Pernambuco, pois a presença negra lá propiciou um aumento do contingente de mulatos. "A diferença entre o mameluco e o mulato - conclui Boxer - acha-se expressa de modo conciso quando se diz que o primeiro não conhecia a mãe, enquanto o último ignorava quem era o pai".

N essa interpretação, "o índio meio-sangue seguia, via de regra, as pegadas do pai", tornando-se um preador dos da raça de sua própria mãe, enquanto 0 mulato continuava um escravo, como sua mãe africana.

Essa discussão sugere a formação de um tipo diferenciado no Planalto de Piratininga. O s colonos, de um modo geral (a julgar-se pelos relatos dos jesuítas), dedicavam-se à preação, o principal negócio da terra. Inclusive todos os funcionários municipais, ligados à Câmara, e membros do clero (excluídos os jesuítas, que defendiam os indígenas, na tradição de Anchieta, e sobretudo de N óbrega) e até mesmo os juízes. D entre esses, destacavam-se al guns que eram considerados os melhores "sertanistas", mais experimentados na organização de uma "bandeira" (termo militar que correpondia a uma companhia de 250 homens "a cavalo e de pé").

E sse ponto de entrada para uma vasta hinterlândia já era muito movimentado no século XVI. Por volta de 1556, portugueses vinham de São Vicente, por 
terra, traficar índios escravos em Assunção, capital do Paraguai. Pouco tempo depois, começam "as devastações em larga escala" efetuadas pelos paulistas, G uairá sendo o lugar predileto desses caçadores de índios, a oeste do Paraná, onde os jesuítas espanhóis ald earam os G uarani para domesticá-los. E ssa "reduções" eram os núcleos agrícolas mais cobiçados pelos paulistas preadores: daí os conflitos violentos entre a I greja e os bandeirantes. O s índios aprisionados trabalhavam na roça, como empregados domésticos, ou eram levados para trabalhar nas minas de ouro eventualmente descobertas (como no Pico do Jaraguá).

E pidemias e trabalho forçado liquidaram tribosnas vizinhanças de São Paulo, o que levou à busca de mais escravos indígenas. D esse modo, em Piratininga olhava-se mais para o sertão, onde a vida rústica a distanciava do modelo europeu das cidades atlânticas. U ma vida pobre, frugal, primitiva, que deixou marca indelével na maneira de ser do "paulistano". O clima temperado do Planalto também explica a possibilidade de se plantar trigo (em 1636, a cifra foi de 120 mil alqueires, cada alqueire correspondendo a treze litros), além de mandioca, hortaliças, arroz, algodão. M ilho, carne e legumes eram exportados, dando uma certa autonomia a essa área, onde faiscava também algum ouro de aluvião, o que justificava a existência na vila de dois ou três ourives e joalheiros. Segundo o jesuíta Fernão C ardim, " as comodidades das casas não são muitas, por serem as mais dellas de taipa, e pal ha, ainda que já se vão fazendo edifício de pedra e cal, e telha". M as o problema, nesta região, estava na falta de tecido para as roupas, que se reduzia apenas aos de algodão.

O governador-geral tinha muita força, mas apenas no plano militar e de defesa. Seu poder era limitado, pois a administração estava nas mãos da câmara ou dos conselhos municipais; podia influenciar, mas não controlar. $\mathrm{H}$ avia um Senado da Câmara, com eleições municipais a cada três anos, tendo direito de voto todo cidadão residente no lugar, e que não tivesse sangue judeu (o que era impraticável em São Paulo), mouro ou africano, ou que (em tese) exercesse atividade ostensiva na indústria ou no comércio (a nobreza portuguesa no Antigo Regime não podia dedicar-se às "Artes M ecânicas", ou "sujar as mãos") .

$\mathrm{N}$ a prática, tais prescrições quase sempre foram desrespeitadas em São Paulo. Além disso, havia uma rotatividade do poder dentro do mesmo círculo de pessoas "boas", da "boa sociedade", como os Pires e os C amargos e seus parentes e sucessores. Essa era uma regra geral, pois o mesmo ocorria, por exemplo, com os Albuquerque em Pernambuco, onde se formou uma oligarquia regional. 0 poder do governador era ainda limitado pelo bispo, sendo obrigado a se submeter a um tribunal superior (da "relação"), que estava na Bahia, desde 1609 sede do Governo Geral. Alguns desses governadores tiveram domínio da língua geral, dos Tupi que habitavam a região; alguns "bandeirantes", como o brutal Domingos J orge Velho, mal falavam o português...

U m certo sentido de independência fez com que São Paulo ganhasse 0 apelido de "La Rochelle do Brasil", nome que evoca a fortaleza protestante que 
resistiu à monarquia francesa da época. $\mathrm{N}$ o fim do século XVII, um governador geral, Câmara Coutinho, homossexual que brutalizava seus escravos, desesperava-se com a insubordinação de São Paulo:

[... ] a villa de São Paulo ha muitos annos que he republica de per

si, sem observancia de ley nem uma assi divina como humana (1692).

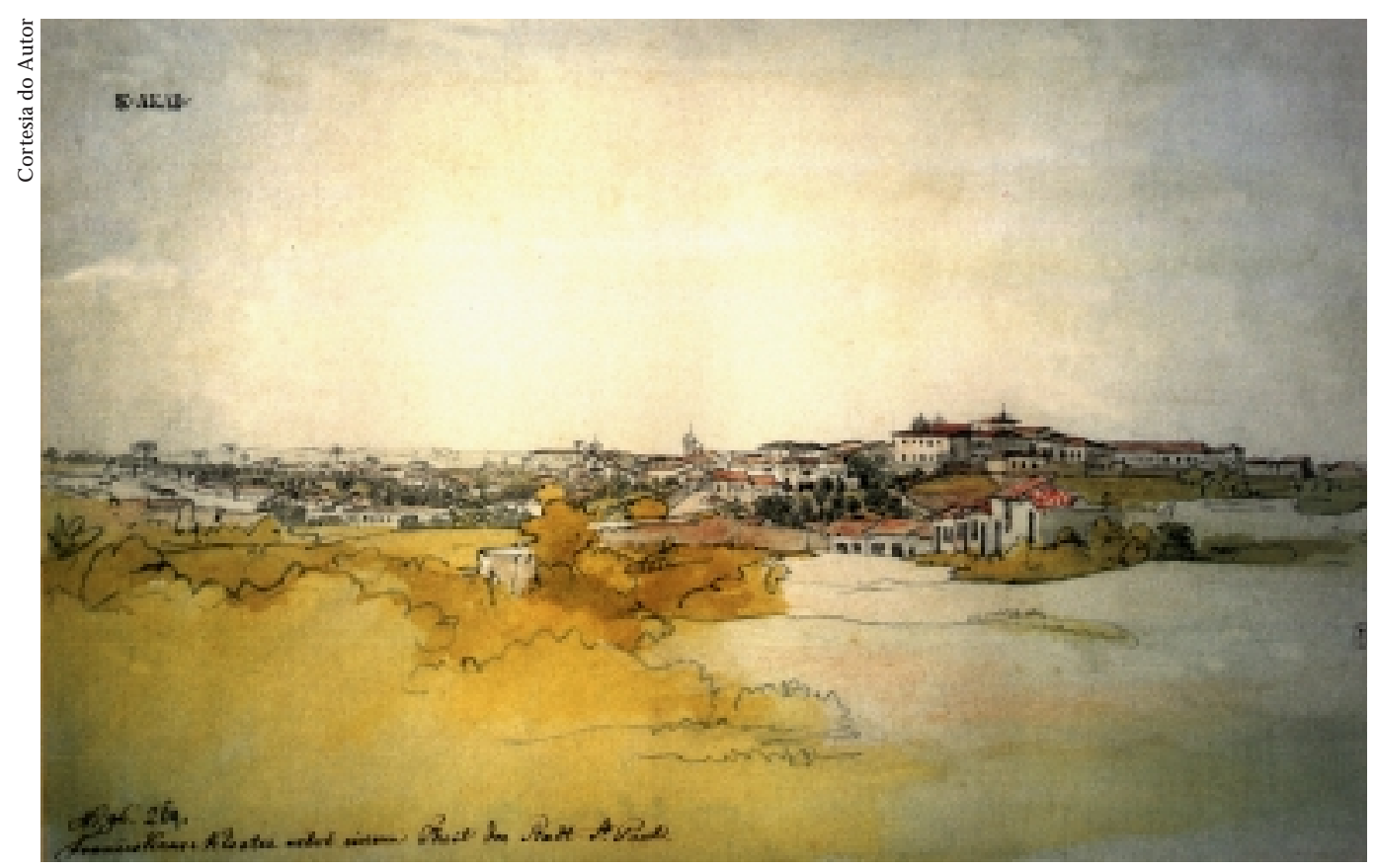

Convento dos Franciscanos, 1817, aquareda, 19,3 x 30,2 cm, por Thomas Ender.

De todo modo, São Paulo fortalecia-se na medida em que estava situada num ponto de comunicação com a Villa Imperial de Potosi, a grande cidade mineradora, onde chegou a existir uma casa da $M$ oeda. $M$ as para quem viesse de Lima, como o padre Ruiz M ontoya, uma cidade como o Rio de Janeiro ou São Paulo pareciam pobres, como "um canto de arrabalde" da capital do vice-reino do Peru, com judeus, muitos insubordinados e preadores de índios...

D essa forma, em São Paulo plasmou-se um outro modelo, uma outra mentalidade. Como era alto o preço dos escravos africanos, e houvesse necessidade de braços para o desmatamento, plantio e todos os outros serviços, inclusive caçar, pescar e guiar as expedições nas florestas, houve um trabalho de aculturação, reunindo-se o gentio em aldeias próximas. Dada a hostilidade de outras tribos, al gumas aceitaram a proteção dos colonos brancos. No caso de São Paulo, muitos Tupi vieram instalar-se nas proximidades, misturando-se com eles e com índios escravizados.

O historiador português ] aime Cortesão viu de modo positivo os " paulistas", como defensores da liberdade e da democracia dos planal tinos contra o totalitarismo teocrático dos jesuítas. M ostrou que os bandeirantes não podiam maltratar os índios cativos, até porque eles constituíam maioria na formação das entra- 
das e bandeiras dos paulistas preadores, e com eles retornavam para aqui viver... Segundo ele, numa bandeira de quatro mil homens, menos de mil eram brancos ou mestiços, sendo os restantes Tupi.

D esfaz-se assim a imagem mítica do "bandeirante". Tal como o gentio da terra, a maior parte andava descal ça, muitos eram mamelucos que, com seus gorros de pano ou de couro na cabeça, viajavam com sementes de milho e farinha de guerra na algibeira. Seus chefes, com suas patentes de comandantes militares, organizavam expedições que reuniam mais de novecentos paulistas e três mil guerreiros tupis, por vezes retornando do Guairá com milhares de prisioneiros guaranis.

Esse é o ponto de partida da história desta metrópole. A té o fim do século XVIII, falava-se no Planalto e na maior parte da Capitania a língua geral, uma mistura de português e tupi. $E$, dada a presença intensa de espanhóis, muita gente também se expressava na língua de Cervantes.

A partir do século XVII surgem esses "potentados em arcos", grandes proprietários de terras e escravos indígenas. E aparecem também os grandes preadores e caçadores de quilombolas negros, que deixariam seus nomes na H istória, como o citado D omingos J orge Velho, vencedor do Q uilombo dos Palmares, na atual Alagoas. Para além da violência, essas figuras eram deixadas um tanto à margem da política da Coroa, até porque iam dilatando o território português definido pelo Tratado de Tordesilhas, e entrando nas terras pertencentes a Espanha. 0 alentejano Raposo Tavares, por exemplo, entrou pelas matas do Paraguai em 1648, subiu o rio M adeira e atingiu o Amazonas em 1652, tornando-se figura épica. N o fim do século, os paulistas descobrem ouro nas futuras M inas G erais, de onde são repelidos pelos "emboabas", portugueses e baianos vindos do litoral. Poucas décadas depois, al cançam as minas de Cuiabá, vivem o ciclo dasmonções, explorando territórios pelos rios, e o chamado ciclo das mulas, o principal meio de transporte que articulou esses vários pontos distantes por terra. A feira de mulas de Sorocaba, até o início do século XX, será uma espécie de pólo articulador da região centro-sul do Brasil, alcançando a Província Cisplatina.

No século XVII, a capitania foi também a grande fornecedora de víveres para o N ordeste açucareiro pois, com a guerra contra os holandeses, cortaram-se muitas das linhas de fornecimento de escravos africanos para as plantações de açúcar e tabaco. Exportou-se trigo, marmelada, um suave perfume de água de laranjeira e outros produtos não-perecíveis.

D esenham-se, assim, a partir de São Paulo, e apesar de ciclos de pobreza e penúria (a riqueza e a urbanização virão somente no século XIX, com o café), as novas fronteiras da futura nação.

N o século XVIII, a cidade passou por uma grave crise, originada pela separação da capitania de M inas Gerais em 1720 e pela cassação de sua própria autonomia, em 1748, pela rainha M aria Ana da Áustria, quando foram também separadas G oiás e M ato G rosso. Foi o rei J osé I quem restaurou a capitania em 1765, nomeando governador a Luís Antonio de Souza Botelho e M ourão, o famoso 
M orgado de $M$ ateus, amigo do futuro $M$ arquês de Pombal. $O$ M orgado se instalou em São Paulo, no Colégio dos J esuítas, de 1766 a 1775, administrando os bens dessa ordem, na orientação da política antijesuítica e reformista de Pombal, déspota esclarecido com "cabelos no coração", como se dizia na época.

Q ue era a São Paulo de então? A vida paulista era morna, o lazer incluía banhos no rio Tamanduateí, pouca coisa mais. D oenças como icterícia e lepra assolavam a população, e a pobreza dominava, levando Pombal a fomentar a atividade agrícola e de comércio, chegando a mandar instalar uma forja de ferro em Sorocaba. Sobre os paulistas, o M orgado escreveu que "gastam tudo quanto têm e vão até o fim do mundo, se necessário. 0 seu coração é alto, grande e animoso, o seu juízo grosseiro e mal limado, mas de um metal muito fino".

No tempo do M orgado de M ateus a capitania tinha sessenta mil habitantes, espalhados em uma cidade, dezoito vilas, nove aldeias e 38 freguesias. São Paulo contava com cerca de quatro mil almas, a vila de Sorocaba era a mais importante, seguida de Santos, G uaratinguetá, Paranaguá, I tu, Taubaté, Parnaíba, Jacareí e Atibaia. N a R elação de Vilas e Freguesias da Capitania de São Paulo, feita em 1765 pelo M orgado de M ateus, aparecem 36 povoações, a capital e nove aldeias de índios. N o primeiro grupo, estão as vilas de M ogi das Cruzes, Jacareí, Taubaté, Pindamonhangaba, G uaratinguetá, e as freguesias de Facão e Piedade. No segundo grupo, as vilas de Atibaia, Jundiaí, M ogi-M irim, M ogi-Guaçu, Parnaíba e as freguesias de J uqueri e Jaguari. No terceiro grupo, as vilas de I tu, Sorocaba, Faxina, A piaí, I tapetininga, C uritiba, Lajes e a freguesia de Paranapanema. Em anotação ao terceiro grupo, o $M$ orgado assinalava também as freguesias de Guarulhos, Santo Amaro, Cotia, Araritaguaba, N azaré e as vilas " porto de mar" de Santos, São Sebastião, São Vicente, U batuba, I guape, C ananéia, I tanhaém, e, na serra, São L uís de Paraitinga.

O utro capitão-general, Bernardo J osé de L orena, mandou calçar o caminho do trecho da Serra do M ar, a "Calçada do L orena". Concluída em 1792, era "um caminho que até de noite se segue viagem por ele [... ], com largura para poderem passar tropas de bestas encontradas sem pararem", segundo o próprio Lorena. Já a ligação São Paulo-R io de J aneiro pelo vale do Paraíba era desimportante. M inas se comunicava com o mundo via Rio de Janeiro, Parati ou Angra dos Reis, e até mesmo à época do café a produção do chamado "N orte" da capitania de São Paulo escoava por lá, e não por Santos. Até a Independência, a comunicação São Paulo-Rio de J aneiro dava-se basicamente por mar, via Santos, persistindo até 0 início do século XX.

I mportante foi, nessa etapa, a lavoura do açúcar, que permite falar num "ciclo paulista do açúcar". N ele foram gerados capitais e condições para a arregimentação de mão-de-obra para o incremento da cafeicultura e o desbravamento dos sertões paulistas. A poiado na economia açucareira, o M orgado, mediante concessõ es de sesmarias, levou a ocupação do solo até à metade do território atual do Estado. Essa ampliação tinha o estímulo do mercado mundial, 
definido-se o chamado "quadrilátero do açúcar", com atividades subsidiárias que deram deram origem à vida urbana da região, como o povoamento de Campinas, que passa a freguesia em 1774, posteriormente sendo elevada a vila, com a estrutura administrativa correspondente. Esse quadrilátero era composto, segundo Caio Prado J únior, por M ogi-G uaçu, J undiaí, Porto Feliz e Piracicaba; mas estudos mais recentes ampliam essa demarcação, preferindo Sorocaba a Porto Feliz, o que inclui definitivamente I tu. A té porque a gramínea teve importância duradoura em Sorocaba, além de ser o pólo fornecedor de muares para os campos de criação da área platina.

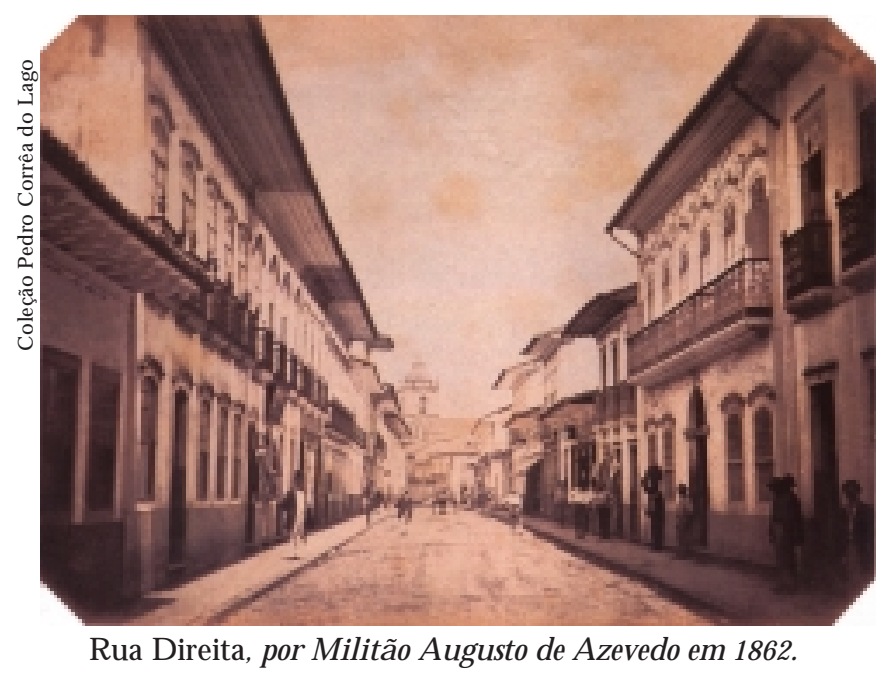

U ma instituição importante dessa época foram os ranchos, construções primitivas que os fazendeiros mandavam erguer para os viajantes à beira das estradas, dada a dificuldade de alojamentos nas casas das fazendas. As descrições - recorde-se as do naturalista francês Saint-H ilaire - revelam um mundo precário, pouco conservado e nada limpo. O s proprietários vendiam milho para a tropa, e os ranchos, muito sujos, "podiam abrigar grande quantidade de mercadorias, mas eram cheios de pó e de lixo, no meio do qual pululavam pulgas e os bichos-de-pé".

À época da Independência, além de São Paulo, já havia no interior alguns centros urbanos de destaque. Jundiaí, e depois Campinas, tornaram-se "nós" no eixo principal da economia e do sistema de comunicações, e serão centros de dispersão de novos caminhos. Como observou o naturalista alemão von M artius,

a vila de Jundiaí é lugar importante para o comércio do sertão. Todas as tropas que partem da capitania de São Paulo para M inas G erais, M ato G rosso e G oiás são aqui organizadas. O s habitantes possuem grandes manadas de mulas, que fazem essas viagens algumas vezes por ano. 0 fabrico de cangalhas, selas, ferraduras e tudo o que é necessário para o equipamento das tropas, assim como o maçante vaivém das grandes caravanas, dão ao lugar feição de atividade e riqueza e, com razão, dão-Ihe foros de porto seco. D aqui partem estradas trilhadas para as províncias acima citadas ${ }^{3}$. 


\section{D a Independência à R epública}

[... ] São Paulo, montanhoso e áspero em partes, tempera a rudeza, a brutalidade dos povos inteiramente montanheses, e habitantes de países gelados; e é sem dúvida o mais capaz de grandes coisas. Ali misturam-se serras com campos, e veigas deliciosas; o frio vence o calor, e dá aos corpos certa energia, que não conhecem os povos de outros climas quentes.

J osé Bonifácio ${ }^{4}$

Com a abertura dos portos às nações amigas em 1808, ano da transferência da Corte para o Brasil, foram levantadas as restrições econômicas impostas à colônia durante três séculos pelo sistema mercantilista português. 0 Rio de Janeiro, onde se estabelecera a sede da monarquia, tornou-se o grande pólo de atividades econômicas, políticas, diplomáticas e culturais do hemisfério sul, articulando a economia destas partes do Atlântico em seus desdobramentos para o resto da América setentrional. O Brasil-Reino entrava para o mapa mundial.

$\mathrm{N}$ a primeira metade do século, no clima das turbulências político-sociais do Primeiro Reinado (1822-1831) e do Período Regencial (1831-1840), alguns centros urbanos adquiriram aos poucos nova dimensão, recebendo muitos desses habitantes recém-chegados de vários países, como se observa pelo $R$ egi stro de Estrangei ros na alfândega. Vilas e cidades do interior, como Vila Rica, Sabará, M ariana, Sorocaba, Guaratinguetá e muitas outras entraram num novo ritmo. Em São Paulo (como em O linda), criou-se, em 1827, a Academia de Direito, para a formação de novos quadros dirigentes. Com a economia o café, que se expandirá no transcorrer do século, se alastrando pelo Vale do Paraíba e litoral e alcançando o chamado O este Velho paulista, a cidade vai polarizar toda uma hinterlândia, beneficiando-se de sua posição privilegiada e fortalecendo sua condição de cabeça-de-ponte para o interior da província.

São Paulo vivera a extrema depressão e pobreza do fim do período colonial. $\mathrm{N}$ ão somente a proibição à atividade manufatureira sufocara qualquer iniciativa nesse sentido, como a dispersão populacional e a autonomia das propriedades rurais não estimulara o desenvolvimento de um mercado para a produção em escala. A indústria em São Paulo não ia além da fabricação manual de algodões e lãs rústicos, de cunho artesanal. C olchas com desenhos esmerados e redes tecidas eram apreciadas, feitas pelas senhoras da "boa sociedade" que se dedicavam ao trabal ho de agulha. $\mathrm{O}$ utras especialidades paulistanas eram a produção de cerâmica, feitas em pequena escala por mestiços nos bairros quase fora da cidade, e chapéus de feltro.

O s ofícios eram controlados pelos escrivães por meio de exames, antes de seus nomes serem aprovados pela C âmara. N o R egistro Geral (1820-1822), consta que quatro sapateiros, quatro alfaiates, dois seleiros, um caldereiro e um carpinteiro foram qualificados como "mestres examinados" ou tiveram autorização para "trabalhar ao público com sua loja aberta". N ote-se que alguns deles eram escra- 
vos, e que passar nesse exame era a condição para o trabal ho, além de reconhecimento de qualificação. No mundo do trabalho, o resto da população era considerada "desqualificada".

$\mathrm{N}$ ada obstante, havia uma certa predisposição, dado o bom clima e o baixo custo de vida, para São Paulo ser considerada por muitos viajantes e cientistas o lugar ideal para um futuro desenvolvimento de indústrias. Além disso, havia já alguma mão-de-obra especializada, sobretudo no setor de couros e madeira, com algum sentido de profissionalização.

Tal ambiente deve ter influído na decisão de D. J oão VI ter transferido do Rio para São Paulo uma fábrica de armas, encarregando dez mestres alemães e cinqüenta trabalhadores do local para tocá-la. Tais alemães ganhavam relativamente bastante, mas se adaptaram demais aos excessos da vida nos trópicos, cedendo aos costumes e à cachaça... A inconstância dos aprendizes brasileiros ao trabalho, numa sociedade escravista, com poucas exigências do meio (que não solicitava mobiliário sofisticado nem acessórios), não levou muito longe a experiência, que só continuaria com subsídios do tesouro real. Também uma fábrica de tecidos estabelecida em 1811 por um português " M estre e fabricante de Tecidos de Sêda e de Algodão" foi fechada. U ma filial do Banco Central foi criada na capitania de São Paulo, para estimular o comércio e a agricultura, mas sem sucesso.

A cidade viveria ainda, segundo o historiador Richard M orse, muitos anos de "inocência econômica". U m levantamento das fábricas da cidade feitas em 1836 demonstra que elas obedeciam ainda ao padrão colonial. 0 fato é que se vivia ainda num contexto em que o valor de um escravo com habilitações ou de artigos importados era mais al to que o custo de terrenos, de mobiliário doméstico local ou de serviços (como visita de médico, por exemplo).

A partir de 1822, ocorre entretanto um significativo esforço por parte do governo provisório local, no sentido de se estimularem as atividades econômicas. C ria-se uma Sociedade E conomica a Benefício da Agricultura e Indústria da Província, com biblioteca, mapas, modelos e "machinas" oferecidos por um notável cientista nascido em Santos e formado em Coimbra, o futuro ministro José Bonifácio. A maior parte de sua vida, ele viveria na Europa, tendo sido professor daU niversidade de Coimbra; com seus irmão $M$ artim Francisco e Antonio Carlos, desenvolveu projetos que deram o estofo político-ideológico para a jovem nação e para a província de São Paulo, dentro da filosofia do reformismo da l lustração.

N os anos seguintes a 1822, surgem iniciativas integrando São Paulo à estrutura administrativa do país independente, ao mesmo tempo em que vai ganhando expressão como centro político da província. M as há uma perda relativa da autonomia municipal, pois os problemas da cidade passam a ser discutidos pelas autoridades da província. Suas necessidades são diluídas no conjunto da província, com soluções de dentro para fora, e não o contrário. Aí estaria a raiz do problema: "seu crescimento, não planejado e tumultuário, iria resultar na megalópolis" 5 . 
Em meados do século, tardiamente, as lideranças da cidade tornam-se conscientes de que deveriam tomar iniciativas no plano econômico e político, para a racionalização dos recursos e empreendimentos. A criação, por exemplo, da Sociedade Auxiliadora de Agricultura, Comércio e Artes (1853) envolvia 59 figuras de todos os setores (engenheiros, professores, padres, políticos), além de agricultores e industriais, que propunham a aceitação de "novos conhecimentos agrários", nacionalização do comércio e substituição do trabalho escravo por métodos mais ligados ao progresso. A essa altura, havia apenas sete fábricas na Província: duas em São Paulo (as únicas com proteção oficial), duas em Sorocaba, e uma, respectivamente, em Bananal, U batuba e Campinas. Somente no ano de 1844 a capital receberia seu primeiro esboço de planejamento urbano, ou meIhor, uma postura de zoneamento simples, com quatro zonas definidas por estradas principais cujo centro era São Paulo, as outras estradas se estendendo ao longo das artérias principais que continuavam para além de dez léguas.

A cidade começava a viver então um regular processo de capitalização, estendendo seu domínio sobre a zona rural sob a forma de empréstimos. São Paulo, como outras na América Latina (Lima, Cidade do M éxico, Rio de J aneiro), liga-se aos grandes centros do comércio mundial, servindo como ponto de conexão de sistemas mais amplos. É o momento em que, no Brasil, desloca-se a vida da casa grande do agricultor da economia do açúcar para o sobrado da burguesia urbana; e, no mundo do trabalho, à passagem das senzalas aos mucambos e, depois, aos cortiços. Com a comercialização e uma produção agrícola em escala, São Paulo passa a atrair um contingente significativo em busca de emprego temporário. M elhoramentos urbanos, como a iluminação a gás, abertura de ruas, lojas com mercadorias diferenciadas, edifícios públicos mais imponentes constituem atrativo não somente para a aristocracia rural que se desloca para as cidades, como para as massas de lavradores desenraizados.

Ao longo do século XIX, essa aristocracia vai se afirmar, expandindo suas atividades para o campo empresarial e político-administrativo provincial e nacional. 0 padre Diogo Antonio Feijó, que chegou a to do-poderoso regente do país nos anos de 1830, era de Itu. Também o M anifesto Republicano de 1870 e a Convenção de I tu em 1873 ilustram essa disposição urbana, liberal e nacional de uma elite, por assim dizer, modernizadora. O s anúncios de jornal (como O Diário de São Paulo) permitem notar que havia mesmo uma rede de tróleis para o transporte dos republicanistas entre São Paulo, Valinhos, Samambaia, Limeira, Rio Claro. Tróleis que, ademais, facilitavam as viagens entre as fazendas e a cidade.

$M$ as foi o crescimento da economia cafeeira que propiciou a construção de estradas de ferro nas frentes de expansão dos investimentos e, em menor escala, de estradas de rodagem. 0 eixo São Paulo-Santos logo seria expandido para os pólos Santos-J undiaí, abrindo um leque ferroviário para o interior da província, alterando profundamente o mapa colonial. A vida socioeconômica dessas cidades e vilas organiza-se agora segundo as linhas de investimento nacionais e es- 
trangeiros, acelerada sobretudo com a imigração em massa de contingentes italianos, espanhóis, mais tarde japoneses, e outros que, ao lado do ininterrupto fluxo de portugueses, daria a marca do novo tempo.

O fenômeno das estradas de ferro foi sem dúvida o mais importante, do ponto de vista da irradiação de um certo padrão de vida urbana, de capitalização e de articulação do resto da Província com São Paulo e com os principais centros mundiais. D ele participaram capitais internacionais, mão-de-obra nacional e de imigrantes, além de iniciativas das lideranças locais. A C ompanhia Paulista (empresa brasileira particular), ligando a São Paulo as cidades de J undiaí, C ampinas, L imeira, Rio Claro e D escalvado; a Companhia I tuana, chegando a Piracicaba; a Sorocabana, em direção a Sorocaba, I panema e T ietê; a M ojiana, abrangendo de Campinas a M oji-M irim, Amparo, C asa Branca, Ribeirão Preto e Poços de Caldas (incorporando o Sul de M inas à esfera econômica de São Paulo) demarcariam o novo sistema econômico-social com fortes implicações políticas regionais e nacionais. $D$ entre as companhias, destaque-se a mais empreendedora e moderna, a Cia. Paulista, que estimulou ainda a navegação a vapor, a navegação fluvial em geral, instalou os primeiros frigoríficos, implementou plantações experimentais, oferecendo empréstimos a juros baixos e material rodante barato às estradas tributárias das estradas de ferro. I nesquecíveis seus funcionários negros dos trens de primeira classe, gentis personagens saídos das páginas de $M$ ark Twain...

A cidade de São Paulo assiste, às vésperas da Proclamação da R epública, ao início de sua modernização. Seus lampiões a querosene tinham sido substituídos em 1872 por iluminação a gás (a companhia concessionária era a São Paulo Gás Co., de Londres), e em 1887 já estavam duplicados os 606 primeiros lampiões, além de estarem ligados à rede 1.430 edifícios. Em 1888, no centro da cidade eram ligadas as primeiras luzes elétricas, precariamente. 0 matadouro municipal foi aberto em 1887 e em 1890 inaugura-se um segundo mercado, pondo fim às barracas populares. Com tanta inovação, os males da civilização moderna também chegavam à nova urbe: com saneamento básico deplorável, a higiene preventiva caminhava a passo s lentos. B rejos e enchentes atormentavam a po pulação com alto índice de mortalidade infantil. E a violência aumentara tanto que, em 1877, os presos da velha cadeia passaram para uma Penitenciária...

Q uanto à água e esgotos, a Cia. C antareira, controlada por empresários locais, trouxe também engenheiros ingleses para abastecer o conservatório da C onsolação. No ano de 1888, 5.008 edifícios já estavam ligados à rede. M as 0 crescimento desordenado e rápido da cidade era inelutável. Para o historiador M orse, os grandes desajustamentos funcionais de São Paulo vêm desde 1880, não podendo ser atribuídos à inépcia ou ao mau-humor herdados da colônia, mas sim ao fascínio que muita gente tinha pela cidade que começava a se dinamizar. Afinal, "as montanhas [da Cantareira] que forneciam água e o Tietê, que carregava o produto dos esgotos de cinqüenta ou cem mil pessoas, tornaram-se insuficientes diante do número dez ou vinte vezes maior". 
Em diversas ocasiões, o poder público tentou tomar medidas para uma racionalização da vida urbana em São Paulo. É o caso do Presidente da Província João Alfredo que, em 1886, propôs "avenidas circulares" que facilitassem aos veículos o trânsito de um subúrbio a outro, sem passsar pelo centro, problema que somente seria equacionado por Prestes $\mathrm{M}$ aia meio século depois. H ouve to davia certa consciência dos problemas criados pela urbanização acelerada, pois al gumas posturas municipais exigiam instalações de esgotos, limpeza e ventilação nas moradias coletivas de classe baixa e, já em 1886, isolamento de "fábricas contaminantes". T ais medidas não eram gratuitas ou assistencial istas, pois derivavam de sérias advertências dos próprios empresários: em 1893, um levantamento das péssimas condições de vida nos cortiços mostrara que o descumprimento dessas determinações municipais estava vitimando grande parte do proletariado. E, na capital, prejudicando o capital.

\section{A industriali zação e a construção da ci dade moder na}

Se senhor não está lembrado, dá licença de lembrar...

Adoniran Barbosa, Saudosa Maloca.

[... ] neste São Paulo frenético que exige a todo instante de cada um des seus filhos que dê tudo em prol de tudo. Eis que não quero nada".

Sérgio M illiet ${ }^{6}$

A construção da cidade moderna foi um processo que se inaugurou na confluência de três acontecimentos históricos importantes: a abolição da escravatura (1888), a instauração do regime republicano (1889) e o surto de industrialização. Embora cada um desses acontecimentos tivesse sua dimensão própria, eles se interligavam, assistindo-se como resultado geral a um significativo deslocamento de capitais e mão-de-obra do campo para a cidade, e a correspondente mudança no equilíbrio político. Esse o fato que marca a entrada da cidade no século XX.

Associado ainda à continuidade do fluxo imigratório, criou-se aqui uma economia industrial com certa estabilidade, se comparada à economia anterior e ao modo como foi administrada, preponderantemente agrícola e sujeita às crises do setor (oscilações do mercado externo e de intempéries). Como denunciaria Paulo Pinto de Carvalho meio século depois:

A cultura extrativa da terra, que o lavrador se viu obrigado a praticar, não pode ser chamada de agricultura. Ela despovoa os campos e faz deles desertos. N ão traz bem-estar nem oferece segurança de estabilidade [... ] I sto mostra que o Brasil tem exportado o seu próprio patrimônio, o seu capital, a sua riqueza representada pela fertilidade da terra, em benefício de um pequeno número de intermediários. Explica-se assim a pobreza de nossa população rural e a prosperidade das cidades, habitação e daqueles ${ }^{7}$. 
Q ue era São Paulo nesse início de século XX? Era o centro de uma constelação urbana mais ampla que incluía as cidades de Sorocaba, Campinas e M oji das C ruzes. E ssa rede se beneficiava de estradas de ferro e de rodagem com acesso ao porto de Santos. Além disso, constituía um mercado consumidor já populoso, diferenciado do resto do país, possuindo matéria-prima para indústrias básicas, como madeiras para móveis e construção, alimentos, cerâmica e olarias, tecidos etc. E uma excelente localização para continuar a desempenhar o papel de centro comercial, de serviços e de agenciamento das relações internacionais, regionais e com outros Estados. D aí a série de hotéis, a Bolsa, lojas, farmácias, a A cademia de $D$ ireito, duas E scolas de E ngenharia e boas escolas secundárias, jornais, restaurantes e serviços em geral (às vezes em ruas que especializadas em tal ou qual ramo de atividade) que dará o tom da nova urbe.

Fenômeno mais importante talvez tenha ocorrido com o capital. E mbora grande parcela deste tenha origem no café, são conhecidas as histórias de fortunas amealhadas por imigrantes, que para cá trouxeram sua capacidade de trabaIho e um "alto senso de negócios", em especial de italianos, sírios, judeus e libaneses. No início muito modestos, lograram, no espaço de duas ou três gerações, construir impérios, atraindo com isso maiores contingentes, como na "febre do ouro". É bem verdade que a imigração foi massiva, pois entre 1908 e 1920 entraram pelo porto de Santos 190 mil imigrantes subvencionados, indo direto para as fazendas, e 340 mil espontâneos, $80 \%$ dos quais foram trabalhar na indústria, no comércio ou em estradas de ferro. N ote-se que muitos deles supriram as deficiências de uma sociedade de passado escravista, servindo como técnicos metalúrgicos e mecânicos, pois o Estado brasileiro e as escolas ainda não possuíam cursos de formação técnica e empresarial. Com as restrições à entrada de estrangeiros nos anos de 1930, por conta da Segunda Guerra, a migração interna - sobretudo do N ordeste e de $\mathrm{M}$ inas - supriu a necessidade de mão-deobra fabril e agrícola. E tal processo não pararia por aí: só a seca de 1952 traria do N ordeste para São Paulo cerca de 1.100 pessoas por dia.

I mportante para o arranque industrial foi a construção de fontes de energia elétrica barata, so bretudo num país em que os combustíveis eram reduzidos e de baixa qualidade. São Paulo teve sua primeira iluminação elétrica estável em 1891, logo aborvida pela São Paulo Tramway, Light and Power Co. Ltd., canadense, que também foi incumbida dos dois sistemas de transporte da cidade. U ma represa, uma usina de força, um sistema de barragens logo seriam construídos para ampliar o potencial da região. A demanda tornar-se-ia espantosa, pois São Paulo registrou, em 1953, uma procura de energia elétrica para cada residência maior que a de Chicago.

$\mathrm{N}$ a entrada do século, já despontava um novo setor da sociedade que não pertencia à aristocracia rural ou urbana, mas também não era proletarizada. E ra uma camada social intermediária, com frações sociais de várias origens, desde a pequena nobreza decadente, profissionais de vários ramos do comércio, funcio- 
nários de lojas, banqueteiros e cozinheiras da alta sociedade, alfaiates e chapeleiros, professores e assim por diante. O s sobrados elegantes do centro da cidade iam sendo readaptados para receber essa classe média, virando pensões que serviam a estudantes, normalistas, advogados, caixeiros, comerciantes, funcionários públiCos, agentes de negócios e toda uma gama de profissionais.

A cidade assistia, assim, ao advento da "classe média", como se pode ler em O Diário Popular de 12 de março de 1892:

A classe média está sendo absorvida pelo elemento estrangeiro, pela considerável massa dos que emigraram para aqui e tomaram conta de toda a pequena indústria, de todo o pequeno comércio, de toda a pequena propriedade e que, enriquecida porque trabalha e gasta pouco, tem amplo e incontestável direito de fazer imposições em seu exclusivo proveito ${ }^{8}$.

N este comentário, com sabor de antecipação, detecta-se o nó de nossa $H$ istória empresarial no século XX: a nova classe trabal ha e gasta pouco, ameal ha, capitaliza, poupa, não é consumista, e além de tudo vai dando vida às pequenas empresas industriais e comerciais. Essa vocação paulistana será a marca que 0 tempo confirmará.

Com a industrialização, a vida paulistana adquiriu um novo sentido. Os homens de negócio, que já procuravam se diferenciar dos "coronéis" do mundo rural, os trabalhadores politizados e uma classe média esclarecida viviam um clima que pode ser sintetizado numa frase de documento do D epartamento Estadual do Trabalho, à época da primeira crise industrial em 1912: "São Paulo é um foco, enfim, prompto para projectar, talvez em breve, uma corrente enérgica em to das as espheras da actividade".

M as o que veio foi mais grave, pois desde o crack de 1892 até a grande depressão de 1929, a economia sofreu reveses que repercutiram no mundo do trabalho. A grande greve de 1917 marca esse período, abrangendo São Paulo, Campinas, Sorocaba e outras cidades adjacentes. N esse quadro, a Semana de Arte M oderna e a criação do Partido Comunista em 1922, elogo depois a R evolução de 1924, surgem como indicações de ruptura com o passado colonial e oligárquico, nessa busca de "modernidade", ou melhor, de atualização do país.

Tal modernidade era também visualizada em figuras como a de Francisco M atarazzo, que construiu, a partir de uma pequena indústria em Sorocaba, depois transferida a São Paulo, um império iniciado no campo dos produtos alimentícios, depois abrangendo desde ensacamento, óleo de caroço de algodão, sabão e artigos de toalete, serrarias, fiação, estamparia, tinturaria e mercerização, chegando a ser agente do Banco di N apoli e da Companhia Fiat. Suas empresas incluíam navios, caminhões, seguros, vagões de trem, seda artificial, álcool, perfumes, vernizes, frigoríficos, fundições etc. U m sucesso, esse M atarazzo que virou conde, seu exemplo tendo estimulado muitas mentes, passando a simbolizar as possibilidades que a "terra bandeirante" oferecia... 


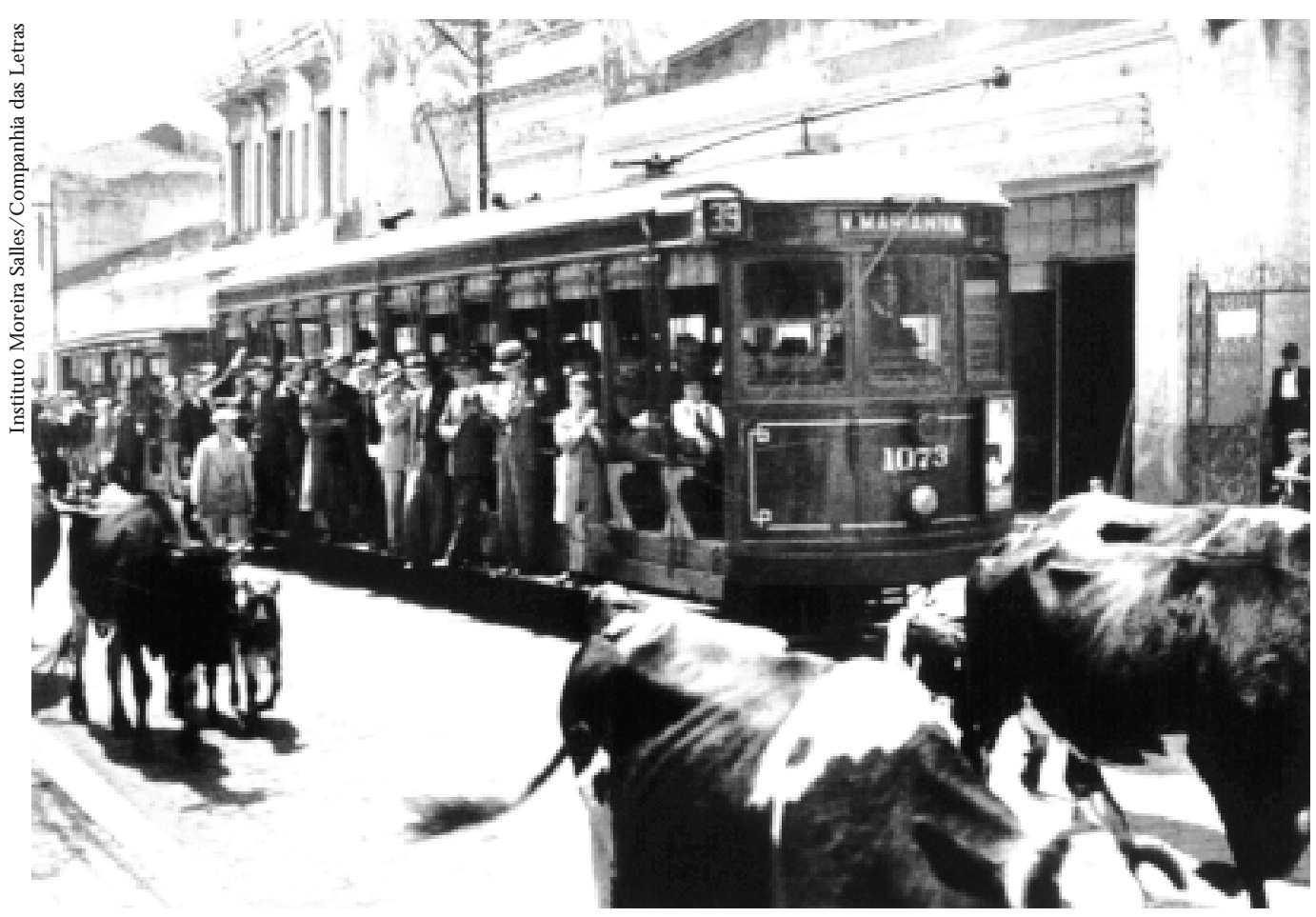

Passagem da São Paulo rural para a urbana regi strada por Lévi-Strauss em 1935.

M as havia um porém: o fato de, como se constatou em 1940, 40\% a 60\% dos moradores da cidade estarem em condições "abaixo do normal". O sucesso não era para todos. O s cortiços se espalharam por vários bairros centrais, e 0 E stado procurou sanar esse problema com as vilas operárias do IAPI em Santo André, O sasco, M oóca, e providenciar estudos sobre o problema do transporte. $\mathrm{H}$ avia o exemplo anterior muito significativo, o da vila operária M aria Zelia, de propriedade do empresário esclarecido e humanista J orge Street, que defendia a distribuição de lucros aos operários e instrução obrigatória aos seus filhos, além de condições decentes de moradia.

O Estado desenvolveu ainda projetos com o apoio de grupos de empregadores para resolver problemas dos trabal hadores, tanto domésticos como legais, buscando formá-los melhor, dando ensino profissional, elevando o padrão de vida e defendendo os salários reais. Para tanto, criaram-se, em 1946, o Sesi (Serviço Social da Indústria) e o Sesc (Serviço Social do Comércio), com a preocupação de formar novas lideranças para posições de direção. A capacitação tornou-se um objetivo real, e para tanto, só em 1946-1947, o Sesil abriu 37 postos de abastecimento na cidade, vendendo até $50 \%$ mais barato os gêneros de primeira necessidade, e forçando assim uma baixa dos preços em geral. Tal exemplo demonstrava o quanto podem fazer para a sociedade e para seus próprios negócios - quando querem - os empresários, em conexão inteligente com o Estado.

Se o exemplo do conde M atarazzo ficou como símbolo da possibilidade de se criar um império industrial e financeiro, outros poderiam ser citados, tanto 
italianos, como sírio-libaneses, portugueses, espanhóis, alemães ou japoneses. Suas origens modestas faziam com que não prestassem muita atenção às teorias vigentes no capitalismo europeu ou norte-americano. Eram mais pragmáticos e atentos às necessidades do consumidor, do cliente. G randes improvisadores, com alto senso de poupança, mas sabendo de suas capacidades. Como nota M orse, "sempre tiveram o cuidado de não depender de agentes, no Brasil ou no exterior, para o capital básico ou para os passos essenciais no processo industrial". Por essa razão, M auá não deu certo no século XIX e M atarazzo foi bem-sucedido no XX, parece admitir o historiador.

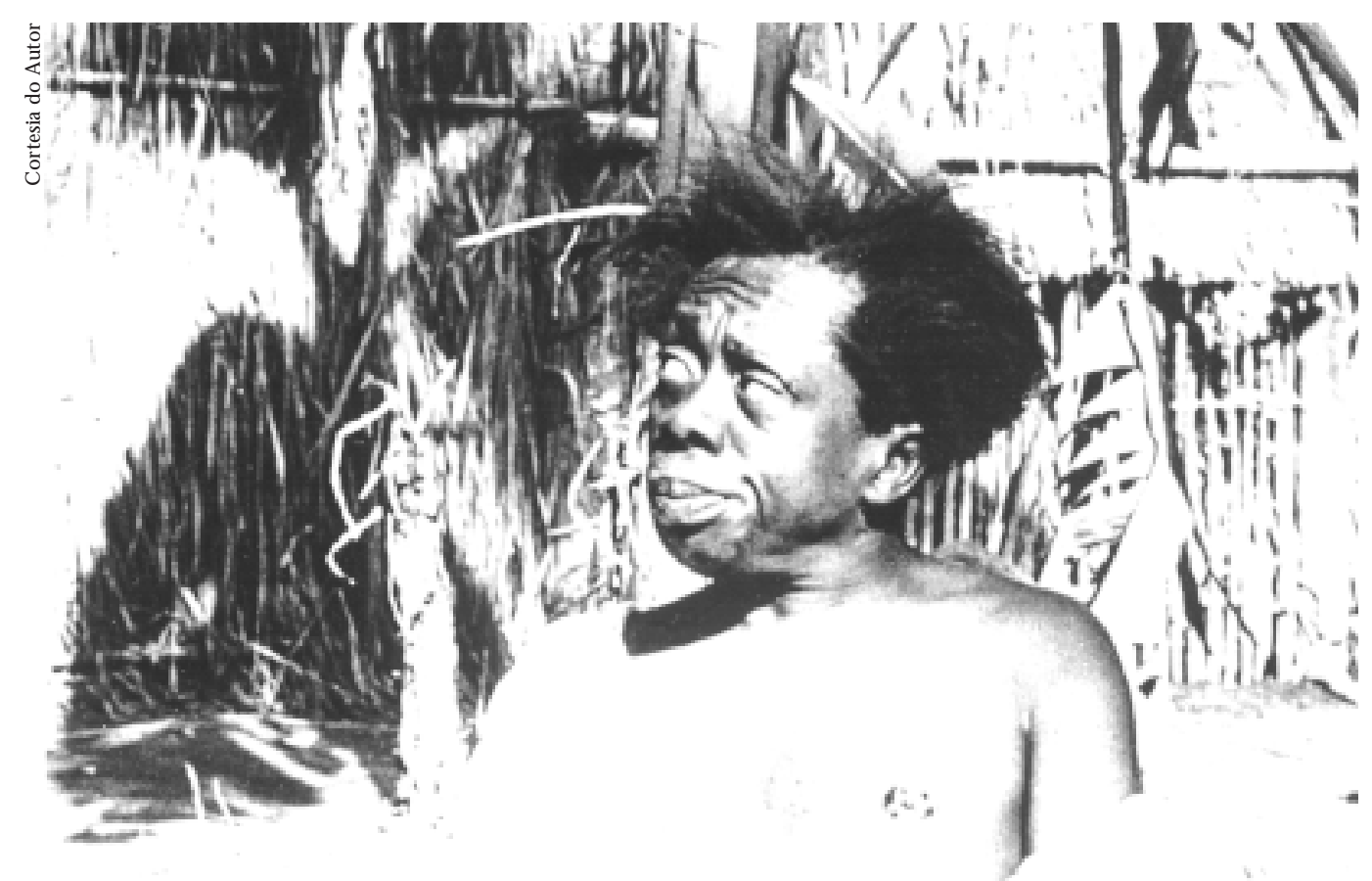

Grande $O$ telo interpreta M acunaíma em filme baseado na obra de Mario de A ndrade.

N ada obstante, São Paulo manteve uma certa tradição de não expansão de firmas industriais de grande porte, fazendo coexistir grandes empresas bem equipadas com pequenas oficinas e com ateliês modestos. E de grandes shoppings com pequenas lojas, em que custos fixos podem ser tornados relativamente baixos. N essa formação econômico-cultural, o trabalhador (assim como o empresário) possui um experiência variada e multiforme, revelando-se apto a exercer papéis distintos.

Relatórios mostram que a variedade social marcou desde o início o arranque urbano-industrial da constelação criada à volta de São Paulo. U m desses relatórios indica que, em 1907, o núcleo de São Bernardo possuía 2.102 pessoas, de catorze nacional idades diferentes, "che vivono in perfetta armonia" cultivando frutas, cereais, legumes, vinhas. Colônias agrícolas circundavam São Paulo, como em São Bernardo e São Caetano a sudeste, com italianos e tiroleses, ou em 
Santana, ao norte, com italianos, alemães e outras nacionalidades. Bairros industriais desenvolveram-se ao longo das linhas de trem, como Santo André e São C aetano, e depois um segundo perímetro de satélites industriais ( $M$ auá, R ibeirão Pires); o bairro da Lapa e do Alto da Lapa; O sasco; Pirituba; Perus e Caieiras; São M iguel Paulista. N ote-se que, se no começo do século São Paulo abarcava somente $5 \%$ da população do Estado, hoje ela representa mais de $30 \%$, com sua população muito ligada às atividades de todo o interior, por meio de empresas suprarregionais e de órgãos do Estado (bancos, organizações sindicais, universidades e escolas etc.).

O que se aprende com esta H istória? Q ue São Paulo possui uma densidade histórica muito especial, com uma tradição de contatos comunitários que vem de longe. Em verdade, possui uma capacidade de absorver e manter traços das culturas que recebe de modo a preservá-las em suas especificidades. U m certo pragmatismo, ou seja, o sentido agudo de práticas concretas criou um ethos próprio, que diferencia a cidade e a constelação a que pertence. Talvez esse o motivo que levou Richard M orse a falar de um "temperamento da metrópole", de uma mentalidade própria.

N o século XX, São Paulo viveria conjunturas em que ocorreram iniciativas positivas em relação ao quadro nacional e internacional, como as adotadas após a crise de 1929: Roberto Simonsen e seus projetos, inclusive o da criação da U niversidade de São Paulo e da Escola Livre de Sociologia e Política foram um exemplo disso. Em São Paulo, no Congresso de Escritores de 1945 realizado na Biblioteca M unicipal e secretariado por Sérgio M illiet, chegou-se a propor que cada empresa com mais de cinqüenta operários mantivesse uma escola de primeiro grau!

E m contrapartida, há que examinar o fato de a indústria automobilística, a partir dos anos de 1960, ter forçado a mudança não somente do porte dos investimentos como do próprio padrão civilizatório, redirecionando toda a história da região. As próprias idéias de cidadee de rede urbana, de urbanização, de civilidade, de espírito de empresa sofreram muito. D epois, a ditadura instalada em 1964 beneficiou a "burguesia predatória" do capitalismo selvagem, amortecendo e desativando algumas das melhores tradições de São Paulo e dos principais centros urbanos paulistas.

Tempos em que se fomentaram iniciativas que mais atendiam à vida urbana do que à vida rural. Em que se verificaram mais apoio à produção de gêneros menos indispensáveis à vida, mas que produziam grandes lucros. E m que se estimularam mais iniciativas que atendiam ao consumismo da hora, pouco ou nada acrescentando à vida e à saúde, à habitação, ao lazer, ao bem-estar, às necessidades básicas das pessoas. A crise se avolumou, os desafios são gigantescos, mas em contrapartida hoje temos uma maior consciência dos problemas, e portanto de suas soluções. 
Terminemos nosso vôo com o historiador M orse. Ele já detectara o problema contemporâneo vivido pelas grandes, pequenas e médias empresas e pela sociedade em geral neste Estado, considerando suas múltiplas dimensões. D entre elas, incluiu o consumidor, a má distribuição de riqueza, o ritmo espasmódico da produção e a influência dos interesses estrangeiros. Em suas palavras:

Ao mesmo tempo que a maioria dos consumidores de São Paulo vive com recursos parcos, a grande desigualdade na distribuição da riqueza leva um pequeno mas bem articulado grupo a pagar preços inflacionários por artigos de luxo que requerem as mais adiantadas técnicas industriais e desviam as forças produtivas dos artigos básicos ${ }^{9}$.

Concluamos. 0 esforço, necessariamente coletivo, dirige-se agora no sentido de se mobilizar o Estado, as lideranças da economia, o mundo do trabal ho, a sociedade e o país para ultrapassarmos os rígidos limites impostos pela história presente, ainda marcada pelo "modelo autocrático-burguês" em vigência (Florestan Fernandes). M odelo em que se combinam negativamente 0 ranço autoritário e a visão imediatista do lucro a qualquer preço. A globalização traz nova carga de desafios, mas também de oportunidades, provocando uma corrida, por vezes exagerada, que obedece ao "ritmo espasmódico da produção, caraterístico de uma industrialização recente, exagerado pela influência dos interesses estrangeiros", segundo a advertência de M orse. D aí a importância de, na ação coletiva, estimular-se uma nova mental idade crítica, que consolide o padrão histórico dessa nova sociedade civil. Q ue surge para domar o capitalismo selvagem. Nova sociedade civil que, por meio de suas iniciativas, com o apoio do Estado democratizado, deve construir e aplicar os filtros para que se processe, aqui, uma globalização sel etiva, separando o joio do trigo. Distinguindo o superficial do essencial, ou o modo da moda, como advertia M ilton Santos.

\section{N otas}

1 Cf. M ilton Santos, M etrópole corporativa e fragmentada. 0 caso de São Paulo, São Paulo, N obel, 1990, p. 3.

2 Alcantara M achado, Vida emortedo bandeirante, São Paulo, M artins/ IN L, 1972, p. 21.

3 J. B. von M artius, em colaboração com J. B. Spix, Viagem ao interior do Brasil, tradução de Lúcia Furquim Lahmeijer, Rio de Janeiro, I mprensa N acional, v. 1, 1938, p. 271.

4 José Bonifácio, in "Caráter Geral dos Brasileiros", s/ d, p.193.

5 Richard M. M orse, Formação histórica de São Paulo. Da comunidade à metrópole, São Paulo, DEL, 1970, p. 74.

6 Sérgio M illiet, D e ontem, dehoje, de sempre, São Paulo, M artins, 1962, p. 123.

7 Apud. Richard M., op. cit., p. 231.

8 A pud Richard M., op. cit., p. 263.

9 A pud. Richard M., op. cit., p. 273. 
Bibliografia

BÓ GU S, L ucia M aria e WAN D ERLEY, Luiz Eduardo (orgs.). A luta pela cidadedeSão Paulo. São Paulo, Cortez, 1992.

BOXER, Charles R. A idade de ouro do Brasil. D ores de crescimento de uma soci edade colonial. 3a ed., Rio de Janeiro, N ova Fronteira, 2000.

BRU N O, Ernani Silva. H istória etradições da cidade de São Paulo. 3a ed., São Paulo, H ucitec, 1984, 3 vols.

CAM POS, Cândido M alta. Osrumos da cidade. U rbanismo emodernização em São Paulo. São Paulo, Senac, 2002.

DEAN, Warren. A industrialização de São Paulo. São Paulo, DEL, 1971.

LEM OS, Carlos A. C. A R epública ensina a morar (melhor). São Paulo, H ucitec, 1999.

M ACH AD O, José de Alcântara. Vida emor tedo bandeirante. São Paulo, M artins/ INL, 1972. I ntrodução de Sérgio M illiet; ilustrações de J. Wasth Rodrigues.

M ARCO NDES, J. V. Freitas e PIM ENTEL, O smar (orgs.). São Paulo. Espírito, povo instituições São Paulo, Pioneira, 1968.

M ATOS, O dilon N . de. Caféeferrovias 3ª ed. revista, São Paulo, Arquivo do Estado, 1981.

M ILLIET, Sérgio. D e ontem, de hoje, de sempre São Paulo, M artins, 1962.

M ORSE, Richard M. Formação histórica de São Paulo. D a comunidadeà metrópole São Paulo, DEL, 1970. Edição revista e ampliada da obra D e Comunidade a M etrópole. Biografia de São Paulo. São Paulo, Comissão do IV Centenário, 1954.

M O U RA, C arlos E ugênio M arcondes de (org.). Vida cotidiana em São Paulo no século XIX. São Paulo, Ateliê/ I mprensa O ficial/ U nesp/ SEC, 1999.

PASSO S, M aria L ucia Perrone (org.). Evolução urbana da ci dade de São Paulo (18721945). São Paulo, Eletropaulo, 1990.

REIS FIL H O, N estor Goulart. São Paulo e outras cidades. Produção social e degradação dos espaços urbanos. São Paulo, H ucitec, 1994.

.U rbanização e modernidade. Entre o passado e o futuro (1808-1945)". Em M OTA, C arlos G uilherme (org.). Viagem incompleta, São Paulo, Senac, 2000, 2o vol.

SANTOS, M ilton. M etrópolecorporativa efragmentada. 0 caso deSão Paulo. São Paulo, N obel, 1990.

SE GAWA, H ugo. Prelúdio da metrópole. A rquitetura eurbanismo em São Paulo na pas sagem do século XIX ao XX. São Paulo, Ateliê, 2000.

SI LVA, J osé Bonifácio de Andrada e. Projetos para o Brasil. São Paulo, Companhia das L etras, 1998. Org. de M iriam Dolhnikoff.

SO M ECK, N adia. A cidadevertical eo urbani smo modernizador. São Paulo, 1920-1939. São Paulo, N obel/ Edusp, 1997.

SOMECK, N adia e CAM POS, Candido M alta (orgs.). A cidade que não pode parar. Planosurbanísticos de São Paulo no século XX. São Paulo, M ackpesquisa, 2002.

SO U ZA, M aria Adélia de. A identidadeda metrópole. São Paulo, H ucitec/ Edusp, 1994.

TO LED O, Benedito Lima de. São Paulo: três cidades em um século. 2aㅡ ed. aumentada, São Paulo, Livraria D uas Cidades, 1983. 
Su má RIO - Co mo São Paulo chega ao século XX, transformando-se numa das três maiores cidades do planeta? Com seu desenvolvimento freqüentemente comparado ao de cidades como L iverpool, M ilão e C hicago, São Paulo possui, entretanto, uma identidade própria, aqui discutida. N este ensaio, o autor oferece uma visão de conjunto dos quatro séculos e meio da $\mathrm{H}$ istória de São Paulo, desde o início da colonização portuguesa até os dias atuais. 0 trabalho está dividido em três partes: das origens à I ndependência (1822); da Independência à República (1889); e industrial ização e a construção da cidade moderna. No percurso, uma reflexão sobre os principais autores que trataram do assunto, de Cortesão e Boxer a Caio Prado J únior, Richard M orse e M ilton Santos.

A Bstract - HoW DID São Paulo become one of the three largest cities in the planet during the $20^{\text {th }}$ century? Although its development is frequently compared to that of cities like Liverpool, M ilan, and Chicago, São Paulo possesses an identity of its own. In this essay, the author offers four centuries and a half of São Paulo's history, from the earliest stages of portuguese colonization to modern times. The essay is divided in three parts: from its origins to Independence (1822); from Independence to Republic (1889); and from industrialization to modern city. Throughout the article, many of the main authors who dealt with this subject, such as Cortesão, Boxer, Caio Prado Júnior, Richard M orse and M ilton Santos, are discussed.

Carlos GuilhermeM ota é professor-honorário do IEA-U SP, titular de H istória Contemporânea da FFLCH -U SP e professor na Pós-G raduação em Arquitetura e U rbanismo da U niversidade Presbiteriana M ackenzie.

Texto recebido e aceito para publicação em 2 de junho de 2003. 